\title{
Modeling of the Temperature-Related Two-Stage Creep Aging for Al-Zn-Mg-Cu Aluminum Alloy
}

\author{
XuFushun ${ }^{1,3}$, Tan Jia ${ }^{1}$, Zhang Jin ${ }^{1,2}$, Deng Yunlai ${ }^{1,2}$ \\ ${ }^{1}$ Central South University, Changsha 410083, China; ${ }^{2}$ State Key Laboratory of High Performance and Complex Manufacturing, Changsha \\ 410083, China; ${ }^{3}$ Kunming Metallurgical Research Institute, Kunming 650502, China
}

\begin{abstract}
In order to model the creep aging process of Al- $\mathrm{Zn}-\mathrm{Mg}-\mathrm{Cu}$ aluminum alloy using common temperature-related two-stage aging, a constitutive framework was proposed considering the creep strain and yield strength. The material parameters involved in the model were estimated using a simple fitting method from the experimental data. With a simple expression, this model is capable of handling stress relaxation, hardening response, and variable aging temperature in the creep aging process. It could also be implemented using finite element analysis software to simulate the creep strain, yield strength, and springback of the component. The modeling results are consistent with the creep strain curves measured under different applied stresses. The numerical simulations are compared with the applied experimental data and excellent consistency is observed between them.
\end{abstract}

Key words: two-stage creep aging; $\mathrm{Al}-\mathrm{Zn}-\mathrm{Mg}-\mathrm{Cu}$ aluminum alloy; constitutive model; yield strength; FEM

Creep age forming (CAF) is a technique originally developed for manufacturing large, integrally stiffened lightweight panels ${ }^{[1-3]}$. Moreover, it has immense potential in future large civil/military aircraft manufacturing industry. Examples of CAF applications include the upper wing skins of Gulfstream IV/V, B-1B long-range combat aircraft, and Airbus A330/340/380 $0^{[4,5]}$. The process combines the creep property of metals and the aging hardening effect of aluminum alloys ${ }^{[2]}$. Generally, the final shape of the work-piece after springback largely depends on the stress state at the end of the creep aging process (after stress relaxation) ${ }^{[6]}$, and the properties of the formed work-piece depend on the microstructure ${ }^{[7,8]}$. However, both the internal stress state and microstructure constantly change, and even affect each other mutually. This indicates that, although the synchronization of the shape and property yields advantages in terms of the production efficiency, the selectable range of the process conditions, such as the applied stress and heat treatment conditions, is also limited. Therefore, the prediction of the formed shape and material property in CAF (referred to "shape-property collaborative prediction"), is particularly important in formulating the process conditions.

In order to predict springback in creep-forming aluminum sheet components, integrated numerical techniques were developed by Ho and Lin et al. ${ }^{[3]}$ using physically based creep constitutive equations ${ }^{[9]}$. Therein, three internal state variables and a hyperbolic sine function were adopted to model the creep behaviors, such as strain hardening, stress relaxation, and tertiary creep softening. Accordingly, Ho et al. ${ }^{[5]}$ developed a set of modified constitutive equations, which included the precipitate growth in 7010 aluminum alloy. With the progress in the research of aging hardening characterization model ${ }^{[10-13]}$, more aging hardening mechanisms have been introduced in the latest proposed creep constitutive models. For example, Li et al. ${ }^{[14]}$ established a creep aging constitutive model for 7B04 aluminum alloy in which the size, shape, and volume fraction of the precipitates were comprehensively considered. Zhan et al. ${ }^{[15]}$ recently proposed a set of mechanism-based creep aging constitutive equations for 7055 aluminum alloy, which modeled creep induced dislocation hardening, solid solution hardening and precipitation hardening.

$\overline{\text { Received date: October 13, }} 2017$

Foundation item: Project of Major State Research Program of China (2017YFB0306301); Project of State Key Laboratory of High Performance Complex Manufacturing of China (ZZYJKT2016-01); National Natural Science Foundation of China (51705539)

Corresponding author: Zhang Jin, Ph. D., Light Alloy Research Institute, Central South University, Changsha 410083, P. R. China, Tel: 0086-731-88876931, E-mail: zhangjinlari@csu.edu.cn 
In our preliminary study ${ }^{[16]}$, we carried out investigations on modeling the creep aging process, and a few improvements and supplements were achieved on the basis of the aforementioned models. The aging hardening model proposed by Zhu et al. ${ }^{[10]}$ was adopted, and the computed results were consistent with the experimental results at constant temperature. Although simplified and equivalent mathematical equations were used, the number of material parameters reached 28. Further, the creep aging of aluminum alloy is an extremely complex process, considering the nucleation, coarsening and distribution of the precipitates, the age hardening effect, and the influence of different creep processing technologies. If all the evolution mechanisms therein are considered, the model will become extremely complicated with numerous material parameters. This development tendency may lead to the loss of practical applicability of the model. Moreover, it is also extremely difficult to solve simultaneous differential equations with various unknown parameters. Furthermore, the existing creep aging constitutive models for $\mathrm{Al}-\mathrm{Zn}-\mathrm{Mg}-\mathrm{Cu}$ alloys ${ }^{[3,14,15,17,18]}$, which are applicable only at constant temperature, cannot be adapted to the common temperature-related two-stage aging processes (such as T74 and T76).

The aim of this study is to establish a constitutive model for the temperature-related two-stage creep aging of $\mathrm{Al}-\mathrm{Zn}-\mathrm{Mg}-\mathrm{Cu}$ alloys. The model can reflect the relationship among the creep strain, mechanical property, and microstructure in creep aging process with a simple expression. Further, it can be applied to finite element analysis as a practical approach for shape-property collaborative prediction in CAF of the $\mathrm{Al}-\mathrm{Zn}-\mathrm{Mg}-\mathrm{Cu}$ alloy components.

\section{Constitutive Model}

Over the common range of aging temperature and time, the creep process of $\mathrm{Al}-\mathrm{Zn}-\mathrm{Mg}-\mathrm{Cu}$ alloys can only undergo primary creep and the secondary creep, and the damage state variables in tertiary creep can be ignored. This temperature range (373 453 $\mathrm{K})$ indicates the intermediate temperature creep of $\mathrm{Al}-\mathrm{Zn}-\mathrm{Mg}-\mathrm{Cu}$ alloys. This kind of creep mechanism, which contains both the dislocation proliferation and dynamic recovery ${ }^{[19]}$, causes a kind of recovery process by which the hardening cannot be completely eliminated; hence, the creep strain has no absolute steady state but invariably shows a downward trend. If the creep of aluminum alloys can be considered as an activation process, the creep strain rate is expressed using the Arrhenius equation as follows ${ }^{[20,21]}$.

$$
\dot{\varepsilon}=A_{\mathrm{f}} \exp \left(-\frac{\Delta H}{R T}\right)
$$

where $R$ is the gas constant $\left(8.314 \mathrm{~J} \cdot \mathrm{K}^{-1} \cdot \mathrm{mol}^{-1}\right) ; T$ is the temperature; $\Delta H$ is the enthalpy change related to the creep activation energy; $A_{\mathrm{f}}$ is the frequency factor that contains the entropy of activation, and it is the function of the applied stress and material structure. Thus, in the creep process of Al-Zn$\mathrm{Mg}-\mathrm{Cu}$ alloys with common aging conditions, the variables related to the material structure are mainly the dislocation and the phase transformation. Thus, $A_{\mathrm{f}}$ can be expressed as follows:

$$
A_{\mathrm{f}}=A \sinh \left[B \sigma(1-d) / \sigma_{\mathrm{y}}\right]
$$

where $\sigma$ is the applied stress, $\sigma_{\mathrm{y}}$ is the room-temperature yield strength, and $A$ and $B$ are material parameters; the variable $d$, which describes the dislocation hardening in the primary creep, is expressed as follows ${ }^{[9]}$ :

$$
\dot{d}=(m / \sigma)\left(1-d / d^{*}\right) \dot{\varepsilon}
$$

where $m$ and $d^{*}$ are material parameters. Eq.(3) demonstrates that the increasing rate of dislocation density slows down gradually and reaches saturation eventually in the creep aging process. It is related to the applied stress $\sigma$ and creep strain rate $\dot{\varepsilon}$.

Thus, the creep aging constitutive equations for Al-Zn$\mathrm{Mg}-\mathrm{Cu}$ alloys can be synthetically expressed as follows:

$$
\left\{\begin{array}{l}
\dot{\varepsilon}=A \sinh \left[B \sigma(1-d) / \sigma_{\mathrm{y}}\right] \exp \left(\frac{k \sigma-Q}{R T}\right) \\
\dot{d}=(m / \sigma)\left(1-d / d^{*}\right) \dot{\varepsilon}
\end{array}\right.
$$

where $A, B, k, m$ and $d^{*}$ are material parameters.

In Eq. (2), the yield strength of the creep-aged materials at room temperature, $\sigma_{\mathrm{y}}$, is used as a material structure variable related to the aging precipitation. On the one hand, it can reflect the aging hardening effect caused by precipitation, which directly depends on the change in the microstructure of the material. Therefore, it is convenient to combine the constitutive equations with the existing aging hardening models. On the other hand, the values of $\sigma_{\mathrm{y}}$ can be easily obtained from tensile tests at ambient temperature. Thus, it can be concluded that the constitutive equation and hardening model are mutually interrelated to and independent of each other. This is the other important advantage of this creep aging constitutive model, in addition to its adaptability to temperature variation. Therefore, the calculation complexity is significantly reduced as compared to the case wherein the constitutive equation is not independent of the aging hardening model. Moreover, Eq. (4) also represents a boundary condition: the creep strain vanishes identically without the applied stress $(\sigma=0)$, which indicates a pure aging process. This boundary condition is important in the CAF of a component with variable curvatures, such as an integral wing panel. As the curvatures of such structural components are continuously variable and mostly small, the corresponding part almost approaches the pure aging process.

For a single-stage creep aging process at constant temperature, the creep strain curves of many $\mathrm{Al}-\mathrm{Zn}-\mathrm{Mg}-\mathrm{Cu}$ alloys can be well fitted by Eq. (4), as shown in Fig.1.

\section{Experiment}

\subsection{Experimental procedure}

Hot-rolled plates of $\mathrm{Al}-\mathrm{Zn}-\mathrm{Mg}-\mathrm{Cu}$ alloy with thickness of 5 $\mathrm{mm}$ were used in the experiments, and the chemical composition is presented in Table 1. The specimens were machined in the rolling direction and the dimensions are shown in Fig.2. After being solution treated ( $743 \mathrm{~K}$ for $1 \mathrm{~h}$ ) and water quenched, 


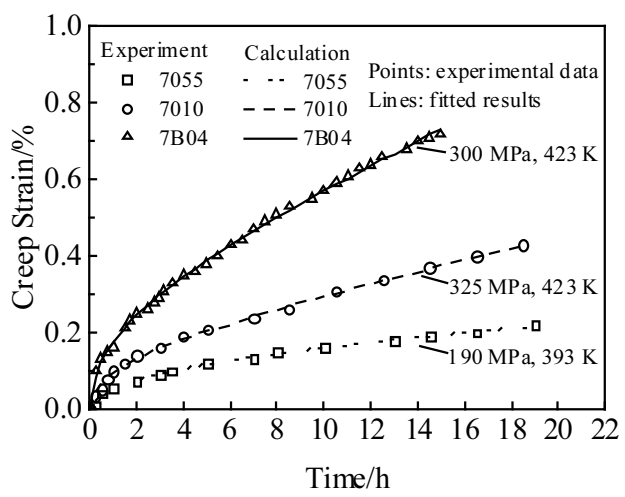

Fig.1 Single-step creep strain curves of $7055^{[15]}, 7010^{[5]}$ and $7 \mathrm{~B} 04^{[14]}$ aluminum alloys

Table 1 Chemical composition of the Al-Zn-Mg-Cu alloy (wt\%)

\begin{tabular}{ccccccccc}
\hline $\mathrm{Zn}$ & $\mathrm{Mg}$ & $\mathrm{Cu}$ & $\mathrm{Fe}$ & $\mathrm{Si}$ & $\mathrm{Cr}$ & $\mathrm{Ti}$ & Other & $\mathrm{Al}$ \\
\hline 5.73 & 2.32 & 1.27 & 0.20 & 0.10 & 0.20 & 0.12 & $<0.1$ & Bal. \\
\hline
\end{tabular}

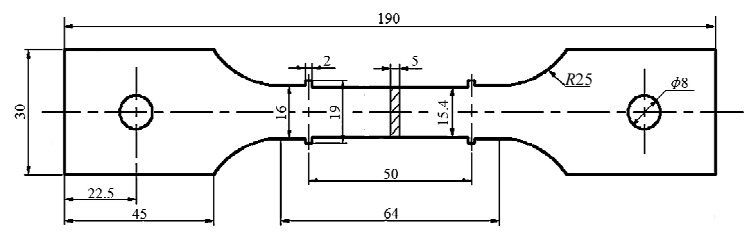

Fig.2 Specimen geometry in creep test

the specimens were maintained in a refrigerated condition to reduce natural aging. Subsequently, constant-stress uniaxial creep aging tests were carried out using a universal test machine with heat equipment. The specimen was fitted and aligned in the middle of the furnace; when the temperature became steady in a short time, a load was applied and the elongation of the specimen was measured. The heat treatment adopted in the tests was the T76 condition ( $394 \mathrm{~K}$ for $6 \mathrm{~h}$ and thereafter $450 \mathrm{~K}$ for $8 \mathrm{~h}$ ), and the tests were repeated for different stress levels $(180,200$, and $220 \mathrm{MPa})$. The room-temperature tensile tests were conducted to obtain the variation of the yield strength.

\subsection{Experimental results and determination of material constants}

Fig. 3 shows the measured yield strength variation during the two-stage creep aging processes at different stress levels. The lines indicate the fitted results, which will be used in computing the material constants. Apparent accelerating transition appears in these yield strength curves at the beginning of the second stage, because the increasing temperature in the second stage may accelerate the process of aging precipitation. Then the yield strength continues to increase and reach the peak eventually. And clear differences could be observed in the yield strength of creep-aged samples under different

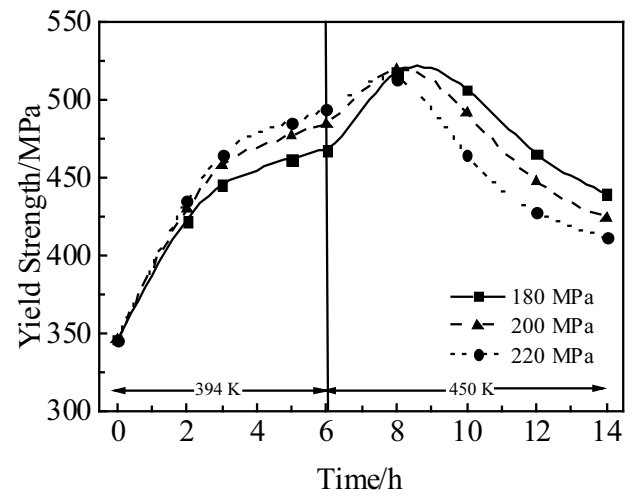

Fig.3 Experimental (symbols) and fitted (curves) yield strength variation of two-step creep aging at different stress levels

stresses: the peak strength is achieved after substantially shorter aging time for the specimens with higher stress level. When it comes to the over aged stage, the yield strength decreases due to the coarsening of precipitates. The variations of the yield strength can be imported to the constitutive model in the form of an existing aging hardening model, or simply in the form of a fitting function of the lines in Fig.3.

Using the variations of yield strength, the material constants can be determined by fitting the creep strain curves using a universal global optimization and evolutionary algorithm ${ }^{[22-24]}$, as presented in Table 2. Fig. 4 shows the computed values of $\Delta H$ at the chosen temperatures and stresses. $\Delta H$ increases as temperature and stress decrease. Moreover, an apparent linear relation appears between the enthalpy change $\Delta H$ and applied stress $\sigma$, and $\Delta H$ varies inversely with the increase in $\sigma$. This is consistent with the studies of Sherby et al. ${ }^{[25]}$ and Ueda et al. ${ }^{[26]}$ on the intermediate temperature creep. Thus, $\Delta H$ can be expressed as

$$
\Delta H=Q-k \sigma
$$

where $Q$ is the unstressed creep activation energy and $k$ is a material constant. The values of $Q$ and $k$ can be easily obtained using the fitted lines in Fig.4, as listed in Table 2.

The calculated and experimental creep strain curves are compared in Fig.5. It is evident that the calculated results are almost perfectly consistent with the experimental results, which indicates that Eq.(4) is suitable for the temperature-related two-stage creep aging processes. Furthermore, Eq.(4) can also be applied in temperature-related creep aging processes with three stages or more, provided that the yield strength curves and the values of $Q$ have been obtained.

Table 2 Values of the material parameters

\begin{tabular}{cccccccc}
\hline$A / \times 10^{3} \mathrm{~h}^{-1}$ & $B$ & $k / \mathrm{mL} \cdot \mathrm{mol}^{-1}$ & $m / \times 10^{5} \mathrm{MPa}$ & $d^{*}$ & \multicolumn{2}{c}{$Q / \mathrm{kJ} \cdot \mathrm{mol}^{-1}$} \\
\cline { 5 - 7 } & & & & & $394 \mathrm{~K}$ & $450 \mathrm{~K}$ \\
\hline 1.02 & 0.25 & 0.228 & 5.66 & 0.994 & 88.6 & 78.8 \\
\hline
\end{tabular}




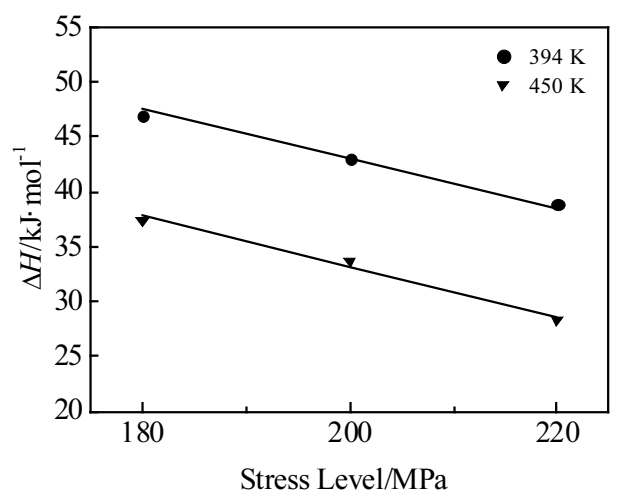

Fig.4 Computed values of $\Delta H$ for different stress levels and temperatures

\section{Finite Element Simulation of the CAF Test and Comparison with Experimental Results}

\subsection{Finite element model}

The constitutive model developed in this paper was implemented using to the finite element software package ABAQUS/Standard (version 6.9) via the user-defined subroutine, CREEP. The static implicit integration algorithm was adopted for a better control of the increments. The finite element model, shown in Fig.6, consists of a stiffened panel and rigid cylindrical tool surface connected by springs. The target radius of the formed panel is $1400 \mathrm{~mm}$, and the designed radius of the rigid tool surface is $820 \mathrm{~mm}$. The plate blank is defined as $\mathrm{Al}-\mathrm{Zn}-\mathrm{Mg}-\mathrm{Cu}$ alloy (Table 1). The thicknesses of the panel and stiffener are 2 and $5 \mathrm{~mm}$, respectively, and the other dimensions are shown in Fig.6. A four-node quadrangular thin shell element was used for the analysis. The material was assumed to be isotropic, and its Young's modulus, Poisson's ratio, and the density of the panel were set as $70 \mathrm{GPa}, 0.33$, and $2.81 \mathrm{~g} / \mathrm{cm}^{3}$, respectively. The simulated external environment of the model was the autoclave, and the air pressure was evenly distributed on the outside surface of the panel. The pressure was set as 0.3 $\mathrm{MPa}$, which was sufficient to force the work-piece to acquire a tool shape. Friction, as a surface interaction property, is related to the contact pair by specifying a friction coefficient of 0.2 to simulate the non-lubricated condition. Moreover, the two-stage aging treatment adopted in the simulation process was the same as the experimental conditions in Section 2.1.

A four-step scheme was adopted in the finite element model, as shown in Fig.7. First, a small but sufficient uniform load was applied to the top of the panel to overcome the stiffness of the four springs and ensure that the four corners of the panel were in contact with the tool surface. Second, the uniform pressure load was applied until the panel was completely in contact with the tool surface. Third, the loading pressure was maintained to hold the work-piece on the tool surface for the creep aging process. Finally, the pressure was removed and the work-piece

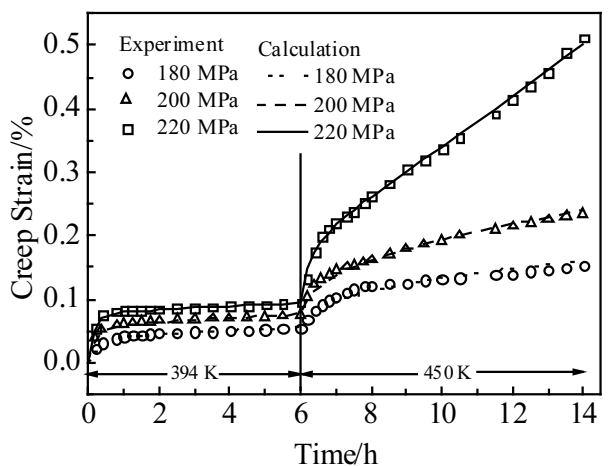

Fig.5 Comparisons of calculated and experimental creep strain of two-step creep aging at different stress levels

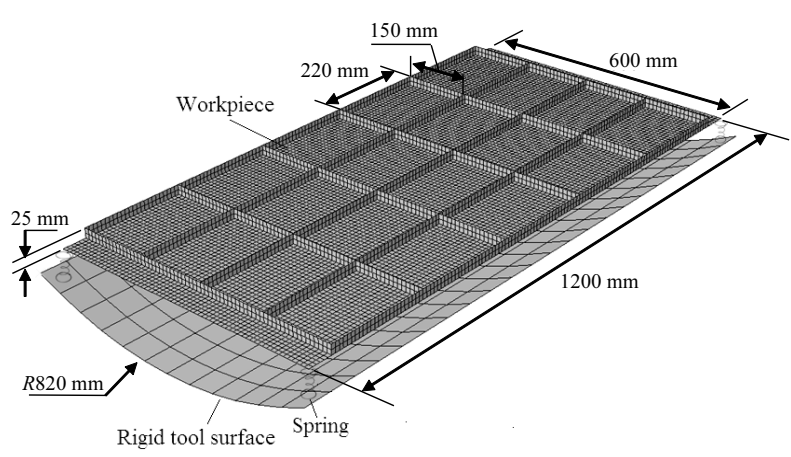

Fig.6 Finite element analytical model showing the dimensions

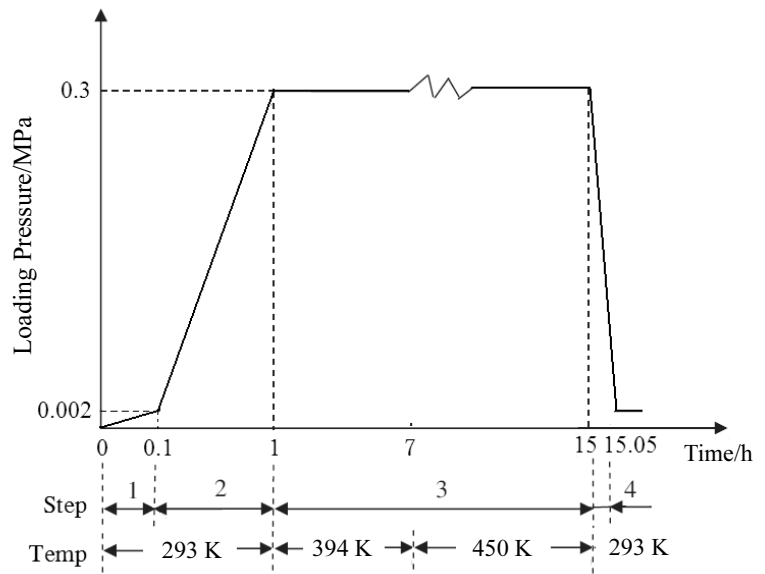

Fig.7 Loading process in the FE simulation

was allowed to springback.

\subsection{Simulation results}

Figs.8a and $8 \mathrm{~b}$ show the creep strain distribution of the forming component at the end of the first stage ( $394 \mathrm{~K}$ for $6 \mathrm{~h}$ ) and second stage ( $450 \mathrm{~K}$ for $8 \mathrm{~h}$ ) of the creep aging, respectively. The main creep strain was generated in the second aging stage, and an apparent difference could be observed in different parts 


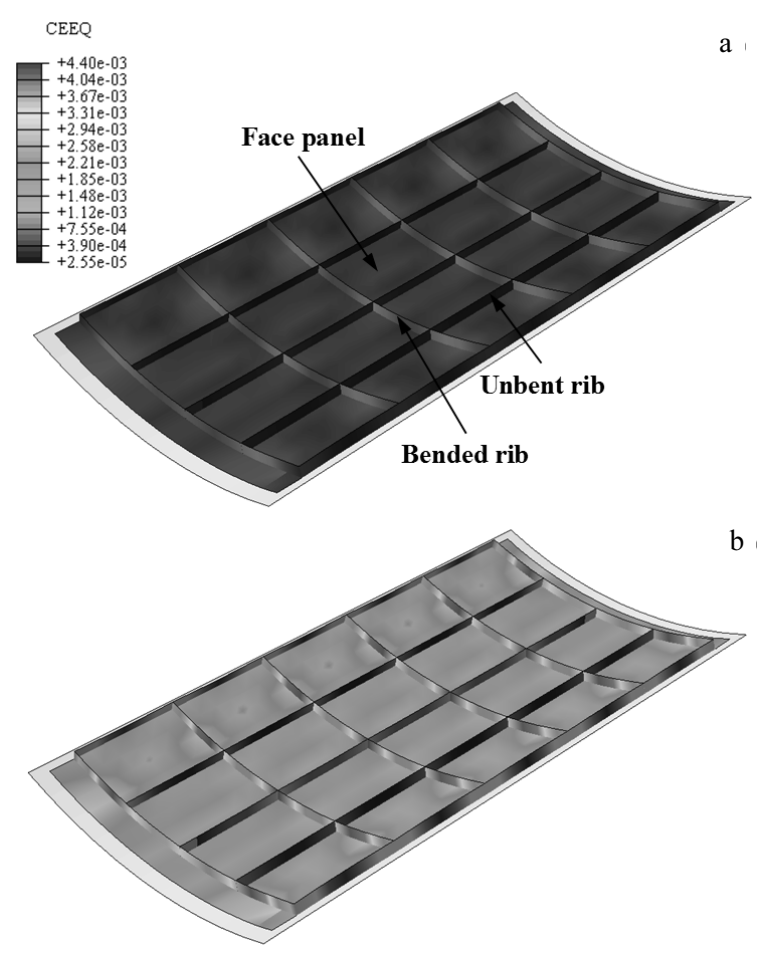

Fig.8 Simulated creep strain contours using the same scale: (a) at the end of the first aging stage $(6 \mathrm{~h})$; (b) at the end of the second aging stage (14 h)

of the component. They can be classified into three representative parts according to the structural features: the bended ribs, unbent ribs, and face panel. The creep strain is distributed mainly in the bended ribs and face panel, and the maximum area is concentrated at the intersections of the bended ribs and unbent ribs. Owing to the small deformation stress, tiny creep strain occurs in the unbent ribs, which could almost be considered as an artificial aged part. The face panel, which occupies the largest area in the component, would not reach the forming requirement if it is only dependent on the creep strain. This is because the small thickness of the face panel cannot produce sufficient bending stress for creep. Therefore, the bended ribs not only play the role of structural strengthening, but also significantly reduce the springback by generating a mass of creep strain, and thus facilitate the realization of the forming goals.

If the field results formed at the end of CAF are treated as the initial state, the springback prediction can be regarded as a static equilibrium problem by solving the initial state. The static implicit algorithm in ABAQUS was used for the calculation of springback, and the final predicted results indicated that the bending radius of the tool surface was $1400 \mathrm{~mm}$. The simulated yield strength distribution nephogram of the formed component is shown in Fig.9. It is evident that there are some differences in different parts of the component. The bended ribs have the highest yield strength, and the maximum value is distributed

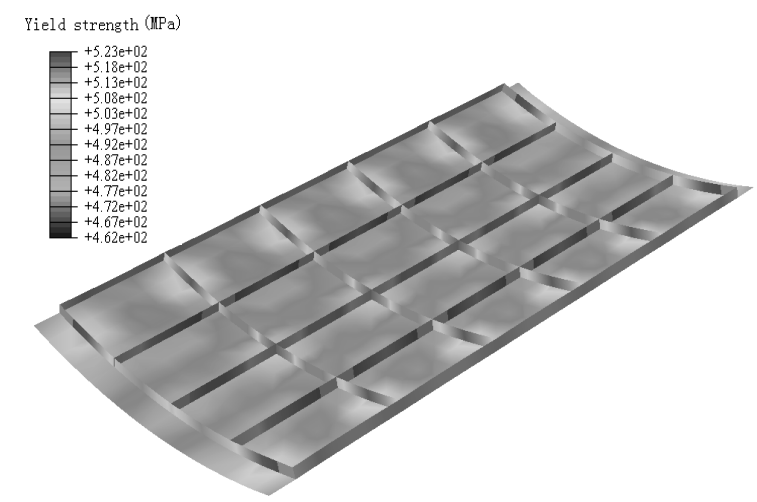

Fig.9 Simulated yield strength contour of the formed component

across the red areas shown in Fig.10. The yield strength of the face panel is lower but more uniformly distributed. The unbent rib has the lowest yield strength, approaching the artificial aging strength.

\subsection{Comparisons between the simulation and experimental results}

In order to verify the simulated results, practical CAF experiments were conducted in the autoclave, and the photograph of the formed component is shown in Fig. 10. The shape of the formed component was measured using an ATOS raster scanner, and the room-temperature tensile tests were conducted to obtain the yield strength. The corresponding schematic of the measuring positions is shown in Fig.11. Lines L1 L6 are the measuring lines to obtain the bending radius of the component, and zones Z1 Z6 are the representative sampling positions for the tensile tests: $Z 1$ is in the face panel, $\mathrm{Z} 2 \sim \mathrm{Z4}$ is in the bended rib, and Z5 and Z6 is in the unbent rib.

The measured results of the bending radius of the formed component are shown in Fig.12, and the dotted transverse line in the diagram denotes the target radius of $1400 \mathrm{~mm}$. The measured results vary slightly because of the shape accuracy of the unformed panel. However, it can be observed that all the measured results are distributed close to the target line within a range of 1395 1406 mm. Hence, the accuracy of the results

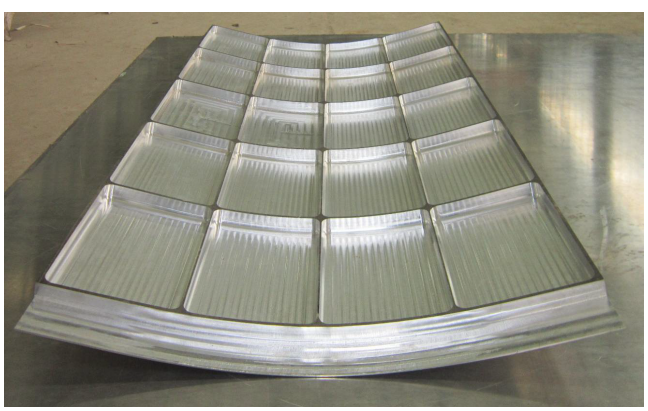

Fig.10 Photograph of the formed component 


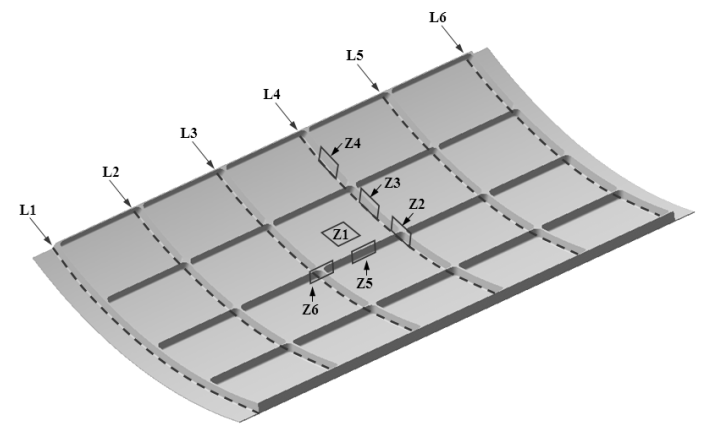

Fig.11 Schematic of the measuring positions for the shape scan tests (L1 L6) and tensile tests (Z1 Z6)

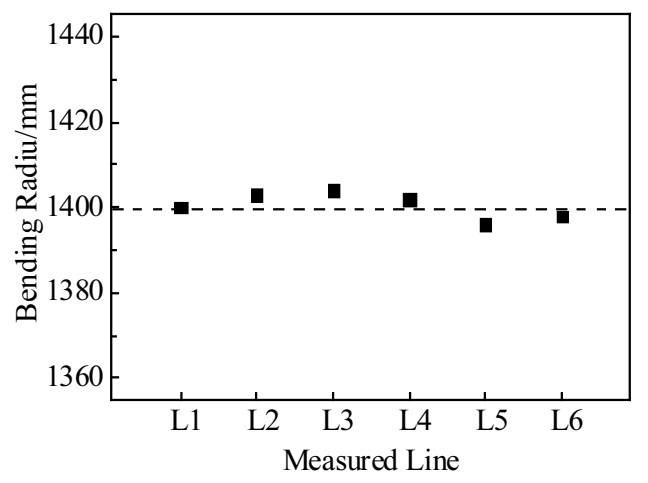

Fig.12 Measured bending radius results of the formed panel, the dotted transverse line denotes the target radius

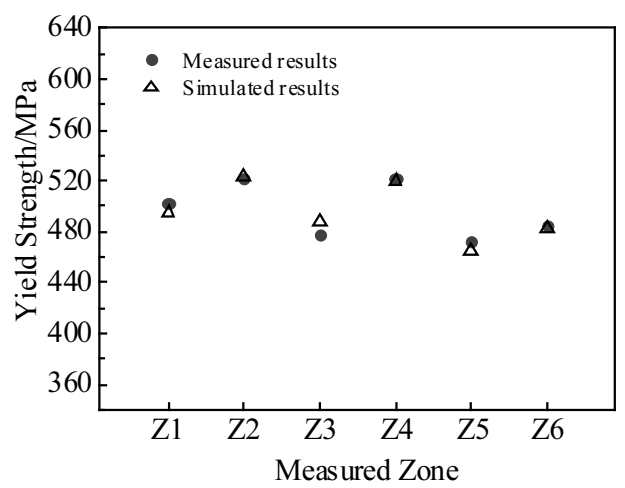

Fig.13 Comparison between the measured and simulated yield strength at different positions of the formed component

predicted via finite element analysis is confirmed. Furthermore, in Fig.13, the measured yield strength values of the samples cut from the typical parts are compared with the simulated results. Obviously, the yield strength in different positions are different from each other. This is because of the different strained condition (or the deformation degree) which has an effect on the strength property in creep aging process ${ }^{[27]}$. The yield strength values in these positions from the measurement are in agreement with that from simulation in the range of experimental errors.

\section{Conclusions}

1) A constitutive framework is developed to model the two-stage creep aging of Al- $\mathrm{Zn}-\mathrm{Mg}-\mathrm{Cu}$ alloys. This model considers the hardening effect and stress relaxation during the creep aging process, and the adaptability to a multistage aging process with variable temperature.

2) The calculation results are consistent with the two-stage creep strain curves under different applied stresses; furthermore, the model could be implemented using finite element software to simulate the creep strain, yield strength, and springback of the component. The numerical simulations are compared with the applied experimental data and excellent consistency is observed between them.

\section{References}

1 Williams J C, Starke E A. Acta Materialia[J], 2003, 51(19): 5775

2 Zhan L, Lin J, Dean T A. International Journal of Machine Tools and Manufacture [J], 2011, 51(1): 1

3 Ho K C, Lin J, Dean T A. International Journal of Plasticity [J], 2004, 20(4): 733

4 Pitcher P D, Styles C M. Materials Science Forum[J], 2000, 331(1): 455

5 Ho K C, Lin J, Dean T A. Journal of Materials Processing Technology[J], 2004, 153: 122

6 Jeunechamps P P, Ho K C, Lin J et al. International Journal of Mechanical Sciences[J], 2006, 48(6): 621

7 Li Y, Nutt S R, Mohamed F A. Acta Materialia[J], 1997, 45(6): 2607

8 Marquis E A, Seidman D N, Dunand D C. Acta Materialia [J], 2003, 51(16): 4751

9 Kowalewski Z L. Journal of Strain Analysis[J], 1994, 29: 309

10 Zhu A W, Starke E A. Acta Materialia[J], 1999, 47(11): 3263

11 Costa T J, Cram D G, Bourgeois L et al. Acta MaterialikJ], 2008, 56(20): 6109

12 Nie J F, Muddle B C. Acta Materialia[J], 2008, 56(14): 3490

13 Esmaeili S, Lloyd D J, Poole W J. Acta Materialia[J], 2003, 51(8): 2243

14 Li C, Wan M, Wu X D et al. Materials Science and Engineering $A[\mathrm{~J}], 2010,527: 3623$

15 Zhan L, Lin J, Dean T A et al. International Journal of Mechanical Sciences[J], 2011, 53(8): 595

16 Zhang J, Deng Y L, Zhang X M. Materials Science and Engineering $A[\mathrm{~J}], 2013,563: 8$

17 Lin Y C, Xia Y C, Chen M S et al. Computational Materials Science[J], 2013, 67: 243

18 Li L T, Lin Y C, Zhou H M et al. Computational Materials Science[J], 2013, 73: 72

19 Ha K F. Microtheory of Metal Mechanic Property[M]. Beijing: Science Press, 1983: 28

20 Spigarelli S, Mehtedi M E. Scripta Materialia[J], 2009, 61(7): 729

21 Sherby O D, Burke P M. Progress in Materials Science[J], 1967, 13(7): 325

$22 \mathrm{Li} \mathrm{B}$, Lin J, Yao X. International Journal of Mechanical 
Sciences[J], 2002, 44(5): 987

23 Lin J, Yang J. International Journal of Plasticity[J], 1999, 15(11): 1181

24 Cao J, Lin J. International Journal of Mechanical Sciences[J], 2008, 50(2): 193

25 Sherby O D, Lytton J L, Dorn J E. Acta Metallurgica[J], 1957, 5:
219

26 Ueda S, Kameyama T, Matsunaga T et al. Journal of Physics: Conference Series [J], 2010, 240(1): 1

27 Zhang J, Wang Y, Deng Y L et al. Materials Science and Engineering $A[\mathrm{~J}], 2016,664: 126$

\title{
$\mathrm{Al}-\mathrm{Zn}-\mathrm{Mg}-\mathrm{Cu}$ 铝合金变温双级蠕变时效模型
}

\author{
胥福顺 ${ }^{1,3}$, 谭 佳 $^{1}$, 张 劲 ${ }^{1,2}$, 邓运来 ${ }^{1,2}$ \\ (1. 中南大学, 湖南 长沙 410083) \\ (2. 高性能复杂制造国家重点实验室, 湖南 长沙 410083) \\ (3. 昆明冶金研究院, 云南 昆明 650502)
}

\begin{abstract}
摘 要: 针对 $\mathrm{Al}-\mathrm{Zn}-\mathrm{Mg}-\mathrm{Cu}$ 铝合金变温双级蠕变时效过程, 建立了一种考虑蠕变应变与屈服强度的本构框架, 通过实验数据的简单拟合 方法获得了模型参数。模型不仅以简单的形式具备了处理蠕变时效过程中的应力松弛、强化响应和温度变化的能力, 而且能够应用到有 限元软件中模拟构件的蠕变量、屈服强度和回弹。模型结果不仅能够适应不同外加应力下实测的蠕变应变曲线, 且有限元模拟结果与实 测结果能够很好地吻合。
\end{abstract}

关键词：双级蠕变时效； $\mathrm{Al}-\mathrm{Zn}-\mathrm{Mg}-\mathrm{Cu}$ 铝合金；本构模型；屈服强度；有限元

作者简介: 胥福顺, 男, 1974 年生, 博士, 中南大学材料科学与工程学院, 湖南 长沙 410083, 电话: 0731-88876931, E-mail: 143106029@ csu.edu.cn 